he was thin his weight was just above the third percentile for his age, in marked contrast to the other patients in this series who were all 0.9 to $6.8 \mathrm{~kg}$. ( 2 to $15 \mathrm{lb}$.) below the third percentile for weight. He responded more adequately to treatment than the others, gaining weight rapidly during the first 18 months of treatment on a "coeliac diet" in 1936 to 1938, to reach the fiftieth percentile for his age, and $1.3 \mathrm{~kg}$. $(3 \mathrm{lb}$.) overweight for his height. From the age of $5 \frac{1}{2}$ years he tolerated a free diet. At the time of the present survey he was symptom-free and $175 \mathrm{~cm}$. (5 ft. 9 in.) in height. He regarded his bowels as constipated (bowel action alternate days) and ate freely of a normal diet. The serum folate level was $3.6 \mathrm{~m} \mu \mathrm{g}$./ ml., $\mathrm{Hb} 14.2 \mathrm{~g} . / 100 \mathrm{ml}$., and blood film normal. It is therefore uncertain whether his original illness was in fact coeliac disease.

The comparative well-being of some of the present patients, in spite of flat or flat with mosaic proximal intestinal mucosa, is in keeping with the observation of Cooke et al. (1963), who found that a flat jejunal mucosa was fully compatible with a normal working life. The most likely explanation seems to be that the clinical state depends not on the severity of the lesion at any one point but on its extent down the small intestine (MacDonald, Brandborg, Flick, Trier, and Rubin, 1964) and on the function of the relatively normal ileum (Stewart $t$ al., 1967).

Nevertheless, six patients had symptoms. One patient had had tetany in adult life, but the effects of malabsorption were confined mainly to evidence of folic acid deficiency. When this form of malnutrition occurs in pregnancy it may be associated with an increased incidence of foetal abnormalities (Hibbard, 1964 ; Hibbard and Smithells, 1965).

Replacement therapy in the present patients was not always sufficient to restore health, and it seems that periodic investiga- tion may be necessary throughout life. If haematological or biochemical evidence of malnutrition is found, treatment with a gluten-free diet appears more rational than the use of dietary supplements. Ideally it may be best, especially for women in the childbearing years, to keep strictly to a gluten-free diet.

It is a pleasure to thank Dr. Bernard Freedman for permission to study patient B. T. ; Professor D. L. Mollin for the haematological findings; Professor I. D. P. Wootton's Department of Chemical Pathology for the biochemical data; Professor C. V. Harrison's Department of Morbid Anatomy for their painstaking work in the preparation of the intestinal biopsies; and Mr. W. Brackenbury for the macroscopic photograph and the photomicrograph.

\section{REFERENCES}

Anderson, B. B. (1964). F. clin. Path., 17, 14

Badenoch, J. (1960). Brit. med. F., 2, 879.

Brackenbury, W., and Stewart, J. S. (1963). Med. biol. Ill., 13, 220

Cooke, W. T., Fone, D. J., Cox, E. V., Meynell, M. J., and Gaddie, R. (1963). Gut, 4, 279.

Crosby, W. H., and Kugler, H. W. (1957). Amer. 7. dig. Dis., 2, 236

Dacie, J. v. (1956). Practical Haematology, 2nd ed. London.

Hardwick, C. (1939). Arch. Dis. Childh., 14, 279.

Hardwick, C. (1939). Arch. Dis. Childh., 14, 279.

Hibbard, B. M. (1964). 7. Obstet. Gynaec. Brit. Cwlth, 71, 529.

Holmes, R., Hourihane, D. O'B., and Booth, C. C. (1961). Lancet, 1, 81. King, E. J., and Wootton, I. D. P. (1956). Microanalysis in Medical Biochemistry, 3rd ed. London.

Lindsay, M. K. M., Nordin, B. E. C., and Norman, A. P. (1956). Brit.

med. F., 1, 14.
MacDonald, W.C., Brandborg, L. L., Flick, A. L., Trier, J. S., and Rubin, C. E.'(1964). Gastroenterology, 47, 573 .'

Roe, J. H., and Rice, E. W. (1948). F. biol. Chem., 173, 507.

Shiner, M., and Doniach, I. (1960). Gastroenterology, 38, 419.

Stewart, J. S., Pollock, D. J, Hoffbrand, A. V., Mollin, D. L., and Booth, C. C. (1967). Quart. भ. Med., 36, 425.

Waters, A. H., and Mollin, D. L.'(1961). ‡. clin. Path., 14, 335.

\title{
Three Cases of Frontal Meningiomas Presenting Psychiatrically
}

\author{
RICHARD HUNTER,* M.D., M.R.C.P., D.P.M. ; WILLIAM BLACKWOOD, † F.R.C.S.ED., F.R.C.P.ED., F.C.PATH. \\ JAMES BULL, $\ddagger$ M.A., M.D., F.R.C.P., F.F.R.
}

\begin{abstract}
Cummary : The clinical presentation of three patients $\checkmark$ with meningiomas at different frontal sites is described. They had been ill for 3,25 , and 43 years before the tumour was demonstrated radiologically. Apathy, incontinence, dementia, and fits were seen in association with middle and superior frontal lesions, and may be mistaken for symptoms of involutional depression or presenile cerebral atrophy. In contrast, excitement and hallucinosis were seen in association with a basal frontal lesion, and may mimic psychotic syndromes like hypomania and schizophrenia, particularly if the tumour encroaches on the third ventricle and adjacent structures. Irreversible loss of myelin and axons in the frontal areas of brain surrounding the tumour may have contributed to the clinical picture of the syndrome shown by these patients.
\end{abstract}

\section{Introduction}

"In the later stages of those cases of tumour in which the mental deterioration is extreme the patient may make no complaints, and the symptoms of 'coarse' lesion may be so little marked as to pass unnoticed. It is obvious that under such circumstances the condition may be mistaken for ordinary dementia. . . . Again, in those rare cases of intracranial tumour in which maniacal symptoms are developed, unless the previous history and course of the case are known to the physician, the presence of a tumour may be unsuspected" (Byrom Bramwell, 1888).

Blackburn's pioneer monograph Intracranial Tumors among the Insane was published in 1903. It was based on the study of 29 cases found in 1,642 necropsies. The majority were what are now called meningiomas and the site of predilection was the frontal region. Such cases may still be missed for a number of reasons. McIntyre and McIntyre (1942) pointed to lack of "tumour consciousness." Morse (1920) blamed the fact that in mental hospitals "the point of view of the physician .... is psychiatric rather than neurologic, and he is preoccupied with the mental symptoms." Furthermore, " use of the term 'organic dementia' as a sufficient designation discourages any refinement of diagnosis." To these reasons may be added lack of investigative facilities and a tendency to ignore physical causes as the basis of mental symptoms until they become obtrusive and the lesion becomes advanced.

* Physician in Psychological Medicine, the National Hospital, Queen Square, London W.C.1; Consultant Psychiatrist, Friern Hospital, Londen N11 and Whittington Hospital, London N.19. t Professor of Neuropathology, Institute of Neurology, the National Hos-

pital, Queen Square, London W.C.1.
$\ddagger$ Radiobogist, the National Hospital, Queen Square, London W.C.1. 
Here we report the cases of three patients in whom, for lack of physical signs early in their illness, the diagnosis was not made for 3, 25, and 43 years respectively. All three had frontal meningiomas and each presented a different, though in retrospect characteristic, clinical picture.

\section{Case 1}

This was a case of progressive dementia of presenile type without focal neurological signs-duration three years.

A married woman aged 62 was referred with a diagnosis of depression. Family and previous history were unremarkable.

\section{History of Present Illness}

She had had frontal headache for three years, at first intermittent and latterly continuous. Two years before admission a swelling appeared in the centre of her forehead which gradually enlarged. $X$-ray examination showed underlying cortical erosion and spiculation of the frontal bone, and the condition was attributed to a low-grade infection. She became depressed and sleepless, and, as the swelling was worrying her, it was explored superficially. At operation some necrotic bony cortex was scraped out. However, her symptoms persisted; she became slow, forgetful, and anergic. Finally, she took to her bed, where she remained for three months. Neurological examination at that time showed no abnormal physical signs, and she was transferred to psychiatric care with a diagnosis of retarded depression. It was thought she was suffering from an organic mental state, which, in conjunction with a history of frontal exostosis, suggested a meningioma. She was therefore admitted to the National Hospital for investigation.

\section{Examination}

On examination there were no abnormal physical signs apart from a fine tremor of the outstretched hands and tongue and generally brisk reflexes. Mentally she was tearful, somewhat confused, disorientated in time and place, and complained bitterly of headache. Psychological testing confirmed a fairly severe recent memory loss with evidence of global dementia without localizing features. She had a mild iron-deficiency anaemia ( $\mathrm{Hb} 10.6 \mathrm{~g} . / 100 \mathrm{ml}$.) and a raised erythrocyte sedimentation rate of $26 \mathrm{~mm}$. in one hour. Electroencephalography showed a marked slow-wave abnormality in the left frontal region.

\section{Radiological Findings}

Skull.-There was an area of enostosis and exostosis in the midline extending over about $3 \mathrm{~cm}$., situated $2 \mathrm{~cm}$. above the frontal sinuses. Small pathological vessels led up from both sides to this lesion. They were branches of each middle meningeal artery. The dorsum sellae was grossly decalcified and thinned, indicating raised intracranial pressure. The calcified pineal gland was displaced $0.5 \mathrm{~cm}$. to the right of the midline and about $2.5 \mathrm{~cm}$. posteriorly and about $1.5 \mathrm{~cm}$. downwards. Conclusions: The appearances were of an almost midline frontal meningioma, extending more on the left than on the right, of massive dimensions as evidenced by the enormous (perhaps unique in degree) backward and downward displacement of the pineal gland, which was lying well in the posterior fossa. The appearances of the sella were consistent with long-standing raised intracranial pressure.

Left Carotid Arteriogram.-The common carotid artery was punctured, and good filling of both internal and external carotid arteries and their branches was obtained. Anterior branches of the middle meningeal artery were hypertrophied and tortuous, confirming the plain $x$-ray findings. They led up to the dura in the anterior frontal region above the frontal sinuses. The left anterior cerebral artery was displaced very grossly backwards and about $1 \mathrm{~cm}$. to the right of the midline. The terminal portion of the internal carotid artery was depressed by the tumour. There was no tumour blush. The internal cerebral vein was displaced grossly downwards and backwards through the tentorium into the posterior fossa. Conclusions : The plain $x$-ray findings were confirmed. A massive tumour, more to the left than to the right, lay frontally and the appearances of the middle meningeal vessels, together with the plain $x$-ray changes, were those characteristically associated with a meningioma.

Gamma Scan (203 $\mathrm{Hg}, 600 \mu \mathrm{Ci})$.-There was a very high uniform uptake in the anterior frontal region measuring about $8.5 \mathrm{~cm}$. in diameter. In frontal view the mass lay across the midline, slightly more left than right.

Summary of Radiological Findings.-Enormous (about $8.5 \mathrm{~cm}$. in diameter) frontal meningioma attached to bone above the frontal sinuses (see Fig. 1).
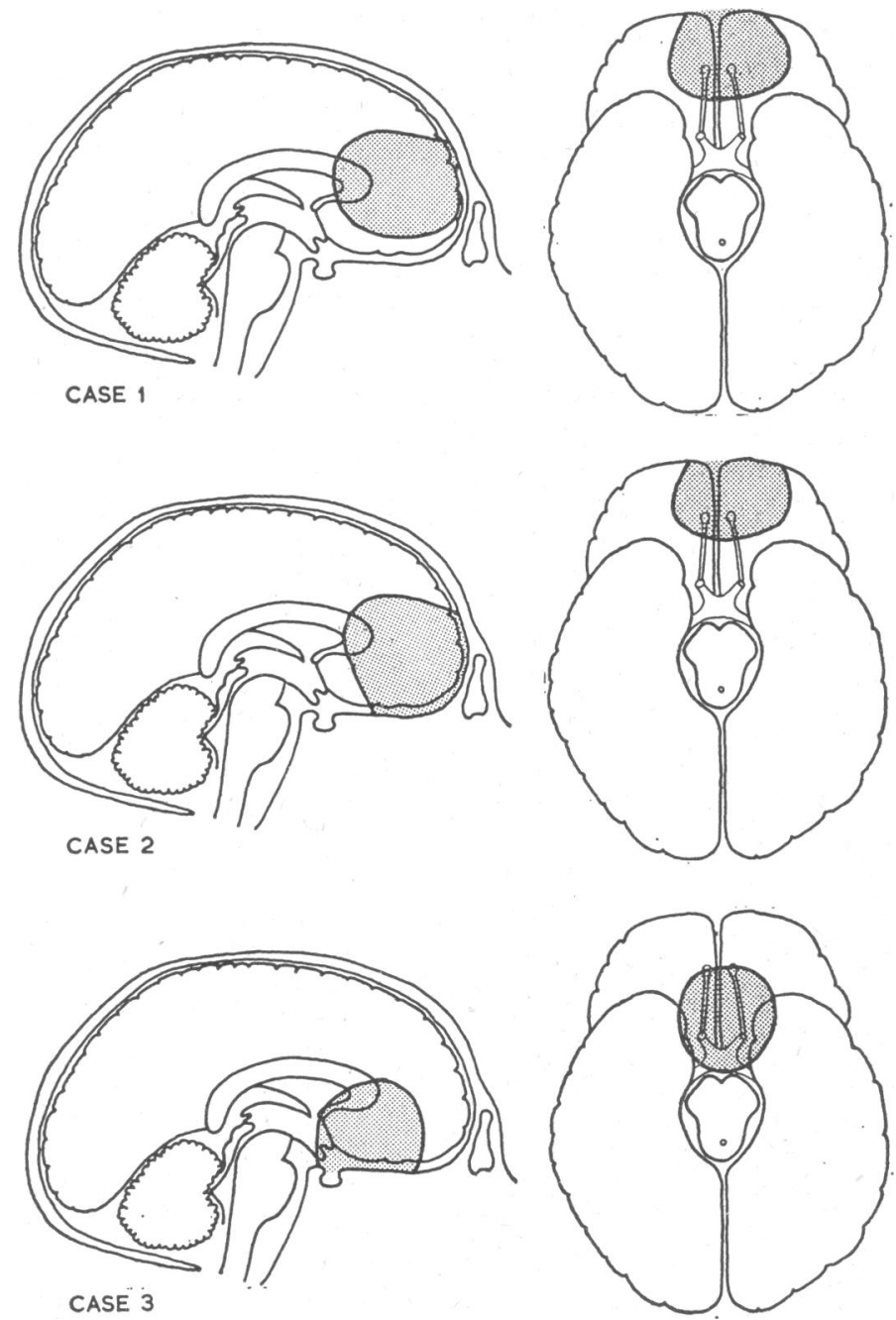

FIG. 1.-Diagrams of lateral and basal views of brain with neoplasm in situ as reconstructed from radiological and post-mortem appearances.

\section{Operation}

A typical parasagittal meningioma infiltrating bone was found The tumour was extremely large (about $8 \mathrm{~cm}$. in diameter), attached to the superior longitudinal sinus and the falx, and extended anteriorly to the crista galli. Some tumour appeared to be infiltrating the bone anteriorly and this was coagulated. The entire tumour and its dural attachment were removed. The frontal poles were seen to be grossly displaced backwards, but the cortex appeared undamaged.

\section{Postoperative Course}

The postoperative course was uneventful apart from a transient state of euphoria and incessant talkativeness, which subsided over the next few weeks. Two weeks after operation her verbal and performance I.Q. had risen from preoperative levels of 81 and 84 to 103 and 97 , but she still showed some impairment of memory, of learning, and on certain tests of abstraction. Follow-up at 12 months showed her to be functioning at her premorbid level. However, a dense amnesia for a period of six to nine months before 
operation persisted. She complained of anosmia and parosmia, presumably due to incidental damage to the olfactory nerves.

At nearly five years postoperatively there were no abnormalities in her nervous system other than total anosmia; parosmia had ceased. Her only complaint was of occasional right-sided headache. Her intellectual functions were consistently good. On formal tests her Wechsler adult intelligence scale I.Q. was 112 , which was 30 points higher than before operation and a further improvement on her score soon after operation. Specific tests for a variety of frontal lobe functions, including ability to execute voluntary and skilled serial movements, and powers of abstraction, showed no remaining impairment. Her memory abilities, immediate, recent, and longterm, were above average, and learning ability for both visual and verbal material was not impaired. It was concluded that she had made a complete recovery (Brenda Clarke).

$X$-ray examination of skull showed recalcification of the sella, and that the pineal had moved about $2.6 \mathrm{~cm}$. forwards and upwards and now lay in its normal position in both planes.

\section{Case 2}

In this case epilepsy started in adult life followed by personality change and optic atrophy-duration 25 years.

The patient was a married woman aged 65 . Family and previous history were unremarkable.

\section{History of Present Illness}

At the age of 40 she started to have grand mal attacks without aura, accompanied by tongue-biting and incontinence, and followed by headache and confusion. At first they occurred weekly, by day or night, later at monthly or longer intervals. She had no recollection of attacks and knew of them only by their sequelae. At the age of 52 she had an episode of status epilepticus, and this recurred every three to four months; in between she had occasional isolated fits or a short run of serial fits. Some of the observed fits were predominantly right-sided and accompanied by a marked rise in blood pressure to $240 / 130 \mathrm{~mm}$. $\mathrm{Hg}$. Neurological investigation at this time showed her to be anosmic, obese, forgetful, and slow. Examination of cerebrospinal fluid and electroencephalography were negative. Skull $x$-ray film was interpreted as showing frontal calcification in the falx. She continued to deteriorate, became apathetic and inert, and finally incontinent and bedridden.

At 53 she was admitted to a mental hospital because she cculd no longer be cared for at home. There repeat $x$-ray examination of the skull was thought to show hyperostosis frontalis interna, and a diagnosis of "Morgagni's syndrome" was made. Psychological examination showed her to be fairly well preserved on verbal items but markedly impaired on performance tasks, with stereotyped errors suggestive of frontal lobe involvement. She was somnolent, aggressive when approached, and her habits were degraded. She continued to have attacks of status epilepticus and sustained two fractures in fits. During the next 12 years her weight, which initially had risen markedly, fell from $13 \frac{1}{2}$ to 8 stone $(85.7-50.8 \mathrm{~kg}$.). At this stage she was seen by one of us and transferred for investigation to the National Hospital with the provisional diagnosis of frontal meningioma.

\section{Examination}

Examination showed a severely demented, somnolent elderly woman with no spontaneous mentation. She responded to questions or commands only very slowly after much prompting and to a limited extent. She sat with her tongue protruded to the right, making purposeless repetitive movements with her right arm and leg. She appeared to be completely anosmic, and could only just distinguish between light and dark. Her pupils reacted sluggishly to light ; there was bilateral optic atrophy with blurring of the disc margin on the right. Her face was asymmetrical at rest and there was a left-sided facial weakness. She was deaf, but its degree could not be assessed. There was no obvious weakness of the limbs, but she could neither stand nor walk. The reflexes were brisk and symmetrical, abdominals were absent, and plantar responses were flexor. No abnormality was found in the other systems; blood pressure was $160 / 100 \mathrm{~mm}$. Hg.
Electroencephalogram showed a marked slow-wave disturbance maximal in the frontocentral region bilaterally with a persistent focus on the right.

\section{Radiological Findings}

Skull.-Curvilinear calcification, with convexity backwards, was present in the posterior part of the frontal region. It could be identified only in the lateral projection. There was some midline thickening of the frontal bone just above the nasion, and the floor of the anterior fossa was very much thinned. The sella showed some degree of pressure atrophy. Conclusions: The possibility of a calcified frontal meningioma was considered and carotid artericgraphy recommended.

Left Carotid Arteriogram.-The common carotid artery was punctured. Good filling of the internal and external carotid arteries was obtained. The intracerebral portion of the internal carotid artery was depressed and the anterior cerebral artery was swept backwards very grossly in a smooth curve corresponding very roughly with the curvilinear calcification noted on the plain $x$-ray films. There was an increase of branches of the external carotid artery leading up to the frontal region. Ethmoidal branches of the ophthalmic artery were hypertrophied. The anterior cerebral artery was deviated about $1.3 \mathrm{~cm}$. to the right of the midline. Conclusions : The appearances were those of a massive bifrontal meningioma, about $6.5 \mathrm{~cm}$. in diameter, more on the left than on the right. It was probably attached just above the crista galli (see Fig. 1).

Gamma Scan.-There was a very high uptake of isotope in the frontal region, corresponding with the position of the tumour shown at arteriography. In supine projection the increased uptake of isotope appeared to be symmetrically situated.

\section{Operation}

Left frontal craniotomy showed the dura to be under considerable tension and involved in tumour. The cortex was found to be a thin lamina stretched over a very large bosselated tumour. This was removed by punch and found to extend across the midline beneath the falx into the opposite frontal lobe and backwards for some $11 \mathrm{~cm}$. from the cribriform plate. Its attachment appeared to be anterior to the cribriform plate; in particular the tuberculum sellae region was clear. Some $5 \mathrm{oz}$. (140 g.) of tumour was removed, estimated to be two-thirds to three-quarters of the total tumour mass.

\section{Postoperative Course}

She made a remarkable improvement, regained a degree of spontaneity, speech, and partial sight, was able to get about, recognized and conversed with relatives for the first time in a dozen years, and became partially continent. She realized she was in hospital, but had a dense amnesia for some 15 to 20 years before operation and misjudged events and ages-for example, of her children-accordingly. On an active rehabilitation programme she improved sufficiently for arrangements to be made for her to be cared for at home-after some 13 years in hospital-when after an attack of status epilepticus she succumbed some five months postoperatively.

\section{Post-mortem Findings}

Necropsy (NH 19/65. Dr. J. Peacock) showed absence of the left frontal pole. The right frontal lobe was displaced laterally by the rounded remnants of the meningioma. This mass extended from the frontal pole as far posteriorly as the coronal level of the temporal poles. It appeared to be arising principally from the inner aspect of the frontal bone, where there was an enostosis. There was no tumour in the region of the optic chiasm or hypothalamus, though the optic chiasm and nerves were very atrophic. The cerebral convolutions were somewhat flattened. The arteries at the base of the brain appeared normal. There was slight dilatation of the ventricular system with some distortion of the lateral ventricles. There was slight bilateral tentorial herniation.

Microscopical examination of the right frontal lobe, lateral and superior to the tumour, showed a relatively healthy cortex but an 
abnormality of the white matter diffusely throughout the lobe. Here there was a "loose" appearance of the tissue and a marked diminution in the number of myelinated nerve fibres; the astrocytes were hypertrophied and there was a considerable astrocytic fibre formation (Fig. 2).

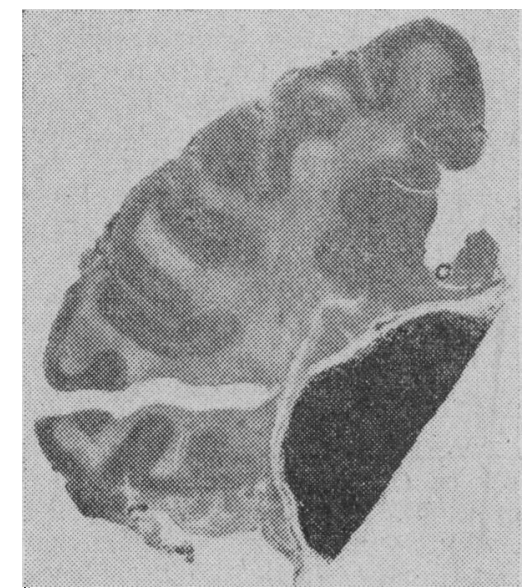

FIG. 2.-Coronal section of right frontal lobe of Case 2 with portion of residual tumour invaginating medial aspect. Note pale staining of white matter indicative of myelin loss (haematoxylin and van Gieson).

Microscopically the tumour was a meningioma composed of bundles and whorls of spindle-shaped cells. Mitoses were not seen. Many whorls had centres composed of collagen or of calcospherites (psammoma bodies). Some small foci of foamy cells were indicative of cellular degeneration. Fine and coarse collagenous stroma was present. Blood vessels were numerous; many had thick collagenous walls.

\section{Case 3}

In this case psychotic illness started at the age of 32 , in the course of which optic atrophy followed by fits developed-duration 43 years.

The patient was a married woman aged 75 . Family and previous history were unremarkable,

\section{History of Present Illness}

At the age of 32 she developed attacks which were described as follows: "She used to fall down as if she had had a stroke and then would not be able to move or speak, though she was not unconscious. Sometimes she would go into a state of coma-for instance, at meals, when she would not be able to hold her knife and fork to eat, or even hold a cup, as her arm seemed to give way. This also happened when she finished her housework. It seemed as if all the right side was affected." At the same time insidious personality change developed; she began to worry about her health and became depressed. She complained of indefinable sensations in her head, and spoke of her attacks as a feeling of losing all her strength or going into " a sleepy state." She was treated by hypnosis and imagined she was being hypnotized at a distance, wondered whether she had venereal disease, and misidentified persons about her. She began to hear voices muttering obscenities, complained to the police of being victimized, and became increasingly preoccupied with her bizarre bodily sensation and hallucinations, and attempted to rationalize them in various other delusional ways. Simultaneously it was observed that she was gaining weight.

On admission to a mental hospital some six months after the onset she was described as "hallucinated in all senses, worried by visions of wild animals and indecent sexual activities, and also by voices." She was extremely excited and voluble. At times she fell and lay " in a fixed position, saying she had been rendered incapable of moving. If one of her limbs was moved she said she had been unlocked and at once regained normal mobility." She accused the doctors and nurses of "hypnotizing her and playing with her brain" and was "somewhat annoyed in consequence." Her eyes, she com- plained, "were being made to work in Morse code." There were no abnormal physical signs and she was diagnosed as suffering from dementia praecox on the basis of her abnormal mental state. Later this diagnosis was changed to dementia paranoides, delusional insanity, and finally schizophrenia.

In hospital her condition remained unchanged except that her delusions, which varied, became more grandiose. She claimed she could read thoughts and so knew everything; complained of being made the subject of medical and sexual experiment, of having organs removed and others substituted, of her thoughts being transmitted by telepathy, of being played on by electricity. Her whole existence was one long torture. Two years after admission as a "certified" patient her husband's request to take her home was "barred." She was then described as sometimes quiet and pleasant, but mostly "garrulous, excitable, wildly deluded, and occasionally impulsively violent." Physical examination again showed no unequivocal abnormal signs: it was noted that her knee and ankle jerks were very brisk, and that she had attacks of " coarse fibrillary tremor of the whole body. She says she "shivers like a dog coming out of water' and takes no notice, as she has done it for some time."

Three years after admission she complained of "being stuck all over with pins and needles; the lower part of her is frozen with cocaine, her inside is moving up and down; wonders whether she is pregnant." At night she is " subjected to the grossest interference ; on one occasion they mistook her for a human telescope, but she did not know what they were looking for." Yet at times she was co-operative and worked in the ward or with a needle, at others "voluble, excitable, rambling, and absurd " but "hilarious." Some 12 years after admission she claimed to be "a lieutenant in the Army, a psychologist at Cambridge, 'the only Marconi woman,' a Chinaman's servant, Horatio Bottomley's sweetheart, half-sister to the Prince of Wales, and heiress to the British throne." She attributed her sufferings to " the 'horrorscope' having been put on her." Her habits were clean and tidy, she spent her time sewing, and there was no gross evidence of dementia supervening.

Seventeen years after admission she was still at times impulsively violent, " because she refers certain visceral hallucinations to persecution and assault by others." So accustomed were her doctors to regard all her utterances as manifestations of a sick mind that when she complained of failing sight they noted: "Still wildly deluded - she believes she cannot see her own image in the mirror." She explained it by a "syphilis germ" having got into her eyes, and described it as "like a piece of string with fibres protruding in all directions from it." After 19 years she had occasional attacks of vomiting. After 25 years she was still preoccupied with being pregnant and asked to have "the present one" removed as she already had " country houses full of children." In other respects she was also "as deluded as ever, especially about wealth, property, and her Army career," but was a good ward worker and intellectually still seemingly unimpaired.

Twenty-six years after admission ophthalmoscopy showed bilateral primary optic atrophy, the beginning symptoms of which can be traced back in her case notes some seven years; and her visual acuity was found to be less than $6 / 60$ in each eye. The possibility of a taboparesis was considered and Wassermann and Kahn tests were performed: both were negative in blood and cerebrospinal fluid. At this time she had her first grand mal fit, and from then on she continued to have fits without aura and followed by confusion every month or more often, and on two occasions sustained fractures. The fits were apparently uninfluenced either in frequency or in severity by anticonvulsant medication. She was also observed to have narcoleptic attacks again, in which she would, for instance, fall asleep over her meals.

Thirty years after admission she was registered as blind. She had then almost doubled her weight to $14 \frac{1}{2}$ stone $(92 \mathrm{~kg}$.). A conversation with her was recorded as follows: "She says she communicates with people in and out of hospital by telepathy and osteopathy ; telepathy is inland and osteopathy overseas. Television helps her to keep dates in her mind, and 'cable vision' enables her to see people all over the world as if they were present. She was not sure whether this was lunacy, but people would be terrified if they knew what went on in her poor body and mind. 'I have all sorts of animals inside me, a tabby cat, a dragon, a platypus which lays eggs and so do I ... there are no less than half a dozen snakes, and if anyone frightens me it makes them put out their fangs and they sting me. I am absolutely stung to death, both physically and financially-they have stung me for half a million." A later note describes her as "still gloriously deluded and full of livestock." 
In view of the history of a persistent abnormal mental state, optic atrophy, and fits she was transferred to the National Hospital for further investigation with a provisional diagnosis of subfrontal meningioma.

\section{Examination}

On examination her mental state was much as described, but her delusions were less florid. She talked ceaselessly, and, being blind and deaf, uninhibitedly in a loud, raucous voice irrespective of day or night and whether there was an audience or not. She was mostly good-humoured but easily irritated. She told the examiner, "Describe me as mad." She was anosmic. There was bilateral optic atrophy, the right pupil reacted very slightly to light but not consensually, the left consensually only. She was deaf, but its degree or type could not be assessed. Her deep reflexes were brisk, abdominals absent, plantars equivocal. Gait, stance, and sensation were normal. No abnormality was found outside the nervous system other than mild hypertension. Electroencephalography was not tolerated.

\section{Radiological Findings}

Skull.-There was a gross pressure atrophy of the sella involving all the dorsum sellae and the posterior part of the floor. The appearances were of raised intracranial pressure, probably chronic, with no localizing signs. The pineal gland was faintly calcified and lay in normal position in the lateral view; it was not sufficiently calcified to be identified with certainty in the anteroposterior view.

Right Carotid Arteriogram.-The common carotid artery was punctured. and good filling of the external but poor filling of the internal carotid artery was obtained. The anterior cerebral artery was displaced somewhat backwards and upwards, and pathologically increased arterial branches of the middle meningeal artery were seen filled in the subfrontal region. Unfortunately no anteroposterior series could be taken. Conclusion: The appearances were of a subfrontal mass-? meningioma (see Fig. 1).

Gamma Scan $(203 \mathrm{Hg}, 600 \mu \mathrm{Ci})$. - There was a high uptake of isotope in the subfrontal and suprasellar regions. The uptake was over a spherical zone about $6.5 \mathrm{~cm}$. in diameter, mainly on the left, but just transgressing the midline. The appearances were those of a subfrontal meningioma.

\section{Operation}

The dura was not under tension. After amputation of the left frontal pole a large meningioma was seen lying on the floor of the anterior fossa. It arose extensively from the dorsum sellae and extended in all directions, entering the middle fossa area posteriorly. Some four-fifths of the tumour was removed by morcellement.

Postoperative Course.-She failed to recover consciousness, was found to have a bilateral hemiplegia, and died two days later.

\section{Post-mortem Findings}

Necropsy (NH 111/64. Dr. T. D, Meek) revealed the absence of the left frontal lobe, and showed recent infarction in the remaining distribution of both anterior cerebral arteries. When the brain was removed the tumour bed was seen to extend from the cribriform plate of the ethmoid posteriorly to the medial aspect of both sphenoidal wings. Medially the tumour extended back to the interpeduncular fossa. It completely surrounded the infundibulum, the intracranial portions of both internal carotid arteries, and the optic nerves. On the right the tumour extended out towards the right Sylvian fissure. In the right frontal lobe as far posteriorly as the corpus striatum there was a noticeable abnormality of the white matter in the regions where it was not the site of recent ischaemic necrosis (Fig. 3). This abnormality consisted of a diffuse, wellmarked diminution in the number of both myelin sheaths and axons, with relative sparing of the subcortical $U$ fibres, with astrocytic hypertrophy and the presence of abundant astrocytic fibres. The overlying cortex showed minor changes only.
Microscopically the tumour showed the appearances of a meningiom'a of arachnoidal type, the cells being often arranged in small whorls, supported by a coarse collagenous stroma, Mitotic figures were not found and blood vessels were not numerous.

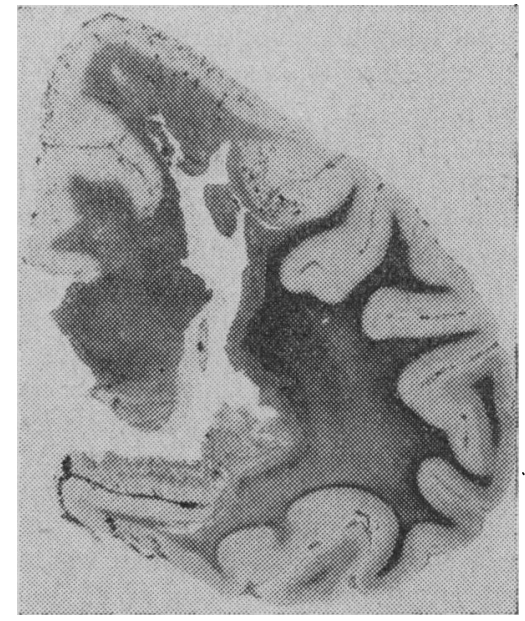

FIG. 3.- - Coronal section of right frontal lobe of Case 3. Upper left: small haemorrhages in cortex and pallor of myelin indicative of recent infarction in the distribution of the anterior cerebral the distribution of the anterior cerebral
artery. Lower right: cortex appears normal, but deep white matter is pale when compared with that close to cortex, indicating myelin loss (Loyez stain).

\section{Discussion}

It appears that intracranial tumours are not found significantly more often in unselected necropsies performed on mental hospital patients than in those dying in general hospitals (Waggoner and Bagchi, 1953-4) despite some suggestions to the contrary (Larson, 1941; Patton and Sheppard, 1956). Klotz (1957) calculated the true incidence in both types of hospital population to be about $2-3 \%$. However, in three respects differences are observed: (1) in the proportion of tumours diagnosed in life; (2) in the frequency with which various types of tumour occur; and (3) in the sites where tumours are most commonly found.

A survey of the literature a decade ago (Klotz, 1957) showed that about half the patients dying in mental hospitals in whom necropsy revealed an intracranial tumour were diagnosed incorrectly. Many reasons could be adduced for this, chief among them perhaps the tendency of psychiatrists to be preoccupied with what one might call "psychosyndromes" and their treatment, with lack of interest in and consequently absence of facilities for investigating the possible physical causes of patients' abnormal mental states. Furthermore, once a patient has been labelled psychiatric the case is rarely reviewed for organic possibilities, least of all in the long-stay wards of a mental hospital. To add to the psychiatrist's diagnostic difficulties not only those patients who cause social disturbance but also those in whom symptoms predominate over signs come under his care. Such a combination is found in patients who have slowly growing tumours at sites likely to cause mental changes early, such as meningiomas involving the frontal lobes (Soniat, 1951) or gliomas involving anterior midline structures (Selecki, 1964). With such lesions localizing signs may not appear until the stage of "final deterioration" as Morse (1920) called it. For these reasons frontal meningiomas are found consistently more often in mental hospital material (Zülch, 1951).

At neurological centres meningiomas account for 14-15\% of all tumours (Kinnier Wilson, 1940 ; Russell and Rubinstein, 1959); in mental hospitals their incidence has varied from $27 \%$ (Larson, 1941) to $50 \%$ (Hoffman, 1937) to as high as 
60\% (Blackburn, 1903). Klotz (1957), who has collated the published series, suggests a true figure is about $33 \%$-that is, at least twice the number seen in neurological practice. With respect to site, in neurological centres about one-fifth of tumours are found to be situated frontally (Kinnier Wilson, 1940), whereas in mental hospitals one-quarter (Patton and Sheppard, 1956) and even one-third (Morse, 1920) may be frontal.

Meningiomas occur most commonly in middle life and more often in women than in men (Cushing, 1938 ; Zülch, 1951). Our three patients were women. Cases 2 and 3 developed symptoms within 12 months of childbirth, an association noted by a number of authors (Bickerstaff et al., 1958). They were aged 59, 40, and 32 at onset, but the diagnosis was not made until they were 62, 65, and 75, though Cases 2 and 3 had been under continuous medical observation for 12 and 42 years respectively. It is of course general experience that of all intracranial tumours meningiomas are the most likely to be missed. In the series of Wood et al. (1957), from the Mayo Clinic, of 300 brain tumours discovered incidentally at necropsy one-third were meningiomas. Cushing (1938) found that the interval between onset of symptoms and diagnosis was on the average eight years, and, exceptionally, as long as 20 or even 30 years. No patient remaining undiagnosed for upwards of 43 years like Case 3 has, to our knowledge, been reported before. This diagnostic time lag, astonishing even in the natural history of meningiomas, may be accounted for in her case by the early onset of " positive"-that is, psychotic-symptoms, which throughout her illness overshadowed the neurological manifestations and to the end masked the silently progressing dementia. However, it is not suggested that the tumour was actively growing throughout this time.

\section{Presenting Symptoms}

In Case 1 the diagnosis was suggested by the history of frontal exostosis, incapacitating headache, and personality change. She presented what may be called the classic form of the disease, a characteristic example of which was described as long ago as 1831 by Bright. Persistent severe headaches are rarely the presenting symptoms of a presenile atrophic process, though this was considered because of her age, dementia, and lack of localizing or lateralizing physical signs. Olivecrona (1934) placed headache first in the syndrome of frontal parasagittal meningioma, followed by insidious personality change and commonly a long history. Because the patient's sufferings were not appreciated as real, her failure to function as a housewife and her increasing apathy had been mistaken for an involutional melancholia or depression. This picture was reinforced by her persistent complaints and her tearfulness, which masked the organic syndrome of which emotional lability was one part. The fine tremor of the outstretched hands and tongue, her only physical sign, which might have been taken as further expressions of anxiety or agitation, is a recognized sign of frontal lesions (Kinnier Wilson, 1940).

Today no patient with dementia who is in long-term psychiatric care can be considered to have been adequately studied without being submitted to the range of investigations available at neurological centres. They may have to be repeated at intervals to ensure that a treatable lesion, such as a meningioma which was too small to detect at the initial examination, does not escape notice. This becomes obvious if anosmia, optic atrophy, or fits supervene, as they did in Cases 2 and 3. Case 2 was under neurological care until she was admitted to a mental hospital. In consequence it was believed that remediable conditions had been excluded.

That surgery is worth undertaking once a frontal meningioma has been demonstrated, irrespective of length of history and apparent degree of dementia, is shown by the recovery in Case 1 and the great improvement in Case 2. Case 1 had been ill for only three years but totally incapacitated for three months. Case 2 had lived a mere vegetative existence for some 15 years, being for much of that time speechless, incontinent, bed-ridden, and blind. Her inability to stand or walk without muscular weakness or reflex change-the astasia-abasia long regarded as " hysterical " but a sign of bifrontal lesions-disappeared postoperatively at the same time as she regained awareness of herself and her environment. Her vision also improved sufficiently so that she could get about again, and she became able to recognize and converse with her family. Had her home not been dispersed because it was believed she was incurable, she would have been well enough to be cared for by relatives. Cases 1 and 2 remained amnesic for the duration of their severest incapacity. Case 2 placed current events such as the ages of her children at some 15-20 years earlier in time.

In retrospect it seems possible that in Case 3 fits and other symptoms may have been aggravated if not caused by blockage of the foramina of Monro by the tumour compressing the third ventricle. However, this possibility was not considered at the time, and diagnosis was made without air study. Had it been, a ventricular shunt of the Torkildsen type, by relieving pressure in the lateral ventricles, might have sufficed at that late stage to prevent further deterioration.

Case 2 also illustrates the association of status epilepticus, either as the presenting symptom or as a recurrent phenomenon, with frontal lesions, in particular those which are bifrontal and involve the central white matter surrounding the anterior horns of the lateral ventricles (Janz, 1964). It may have been caused by direct pressure of the tumour or by the secondary changes seen in the surrounding white matter. Both Cases 2 and 3 showed evidence of extensive loss of myelinated nerve fibres from their remaining frontal lobe. In Case 2, who survived operation five months, it was not possible to be certain that this disorder had been present at the time of operation. In Case 3, however, who survived only two days, the evidence was unequivocal that extensive damage to frontal white matter had been present before operation. These changes were compatible with, but not diagnostic of, those seen in response to cerebral oedema. This is a frequent finding in white matter adjacent to neoplasms, particularly meningiomas and secondary carcinomas. Its pathophysiology is not clear, but it seems that the longer the tumour remains in situ the more likely are these irreparable changes to appear and the greater their extent. This complication adds further urgency to early diagnosis. Case 1 was fortunate not only in her comparatively short history but perhaps also that her tumour displaced the frontal lobes backwards. Her complete recovery of personality and intellectual function, confirmed by psychological testing, suggests that frontal lobe damage had either not occurred or was mild.

The postictal confusion shown by Case 2 which early in the illness led to prolonged fugue states, as well as her postictal headache, is also in keeping with a lesional epilepsy. Headache and confusion also followed fits in Case 3, but may have been due to obstructive hydrocephalus. At first they occurred singly, later in small runs. One episode of serial fits was induced by lumbar puncture performed before the diagnosis was established, when, incidentally, the cerebrospinal fluid was found to contain $260 \mathrm{mg}$. of protein per $100 \mathrm{ml}$. and an excess of globulin.

The incontinence unrelated to fits which Case 2 showed was taken for a sign of personality deterioration and loss of social sense, and was one of the reasons why she was admitted to a mental hospital. It is now known that incontinence of this kind results from medial frontal lesions which impinge on the micturition centre anterosuperiorly (Andrew and Nathan, 1964). "Morgagni's syndrome," dating from the eighteenth century and consisting of hyperostosis frontalis interna, dementia, and obesity, which was diagnosed at one stage of her illness, should now have ceased to have nosological validity (Smith and Hemphill, 1956). Like many eponymous syndromes it dies hard, though almost 150 years ago Malherbe (1833) showed that frontal meningiomas produced the clinical picture associated with it. Hyperostosis frontalis interna is in 
fact bifrontal and spares the midline, while meningioma hyperostosis is nearly always unilateral or midline.

Both Cases 2 and 3 became markedly obese. Case 2 gained 4-5 stone $(25.4-31.7 \mathrm{~kg}$.) and Case $37-8$ stone $(44.5-50.8 \mathrm{~kg}$.), which almost doubled her weight. Neither was obviously bulimic or hyperphagic. Logue et al. (1968) observed similar striking weight gain without corresponding increase in appetite in patients who survived rupture of an anterior cerebral artery aneurysm. Presumably in their cases the same region of the brain was damaged. The obesity of our patients, like the somnolence and anergy of Case 1, the hypertension recorded in fits in Case 2, and the narcoleptic and akinetic attacks of Case 3, was therefore probably caused by damage to hypothalamic centres at and around the anterior end of the third ventricle, whether by direct pressure or distortion. Indeed, weight gain occurring in the course of a psychiatric syndrome, especially in middle or later life, should be regarded as suspicious of underlying cerebral disease. This is in keeping with the old empirical observation that weight gain without coincident mental improvement indicates a poor prognosis (Bucknill and Tuke, 1879).

\section{“ Positive" Symptoms}

In contrast with the "negative" symptoms of apathy, unconcern, and dementia which characterize lesions of the dorsal and middle portions of the frontal lobes, lesions affecting the base of the frontal lobes or orbital cortex and extending back to the infundibular region may be marked by "positive" symptoms-that is, excitement, disinhibition, and euphoria (Faust, 1966). The mental state of the patient of Arseni et al. (1966) was indistinguishable from hypomania, and the same was seen after orbital leucotomies (Le Beau et al., 1954). It was the prevailing picture shown by Case 3 almost throughout her illness, in the course of which she developed optic atrophy after 18 years, and fits a quarter of a century later. In fact, had not Kraepelin's classification forced a division between dementia praecox or thought disorder and manic-depressive psychosis or affective disorder, "chronic mania" would have been diagnosed. Her illness began with attacks which are identifiable as narcolepsy, cataplexy, and akinesis or trance states, followed by right-sided weakness. They closely resembled those sometimes seen in patients with lesions in or around the third ventricle, such as a colloid cyst. Such patients may also have periods when they are excited and "wildly deluded," as, for instance, Kelly's (1951) Case II. In our patient the abnormal mental state persisted, though she too had times of greater excitement and rarer periods of comparative calm.

Of great theoretical interest for cerebral localization of psychiatric symptoms are her bizarre somatic illusions and hallucinations of hypochondriacal type, as well as the early, vivid, formed visual hallucinations. In contrast, auditory hallucinations remained in the background, another pointer to the "exogenous" nature of her psychosis (Bleuler et al., 1966). Commensurate with her good intelligence and wit, she elaborated them richly into fantastic delusional themes. Not surprisingly, in the framework of a classification which remains predominantly symptomatic, she was diagnosed as suffering from "schizophrenia," since she showed the supposedly pathognomonic signs. Yet simultaneously she exhibited the cardinal features of "hypomania " : exaltation, pressure of talk, and good humour alternating with irascibility, and Witzelsucht with a tendency to pun and "clang" associations, of which examples have been given. Doubtless some of these features, such as concreteness of thought and disinhibition, were aggravated by the secondary frontal myelin and axonal loss revealed at necropsy. However, that such states of persistent excitement with hypomanic colouring may occur independent of frontal involvement, with lesions affecting chiefly the floor of the third ventricle and adjacent structures, was shown by another patient, a woman in her sixties who presented in this way without any physical signs. Routine skull $x$-ray examination showed the typical ballooning of the pituitary fossa of chromophobe adenoma. Her " hypomania" subsided with radiotherapy, and three years later had not recurred.

\section{Visual Hallucinations}

Formed, differentiated, and complex visual hallucinations are usually taken to occur mainly in temporal lobe tumours due to irritation of the optic radiation (Huber, 1961) and then commonly accompany dreamy states with olfactory and gustatory hallucinations in the so-called uncinate fit. Lhermitte (1951), however, pointed out as early as 1922 that some patients with lesions of the upper midbrain, interpeduncular fossa, and median hypothalamic or juxtapituitary region have persistent visual hallucinations, with or without other signs of mesencephalic or diencephalic involvement. In Case 3 the tumour extended laterally to the medial aspects of the temporal lobes, but there is no record of temporal lobe type of fits. Posteriorly it reached to the interpeduncular fossa, and it is possible that irritation at this site was responsible not only for her original symptoms but also for her persistent visual hallucinosis. A like case of peduncular hallucinosis in a patient with a pituitary tumour was abserved over eight years by Redlich (1912). He also developed ideas of persecution, and, like Case 3, his hallucinosis was particularly marked at night.

It should be remembered that in the early 1920s, when Case 3 fell ill, the underlying lesion could not have been confirmed even if suspected. Neither clinical knowledge nor techniques of neurological investigation were sufficiently advanced. By the time it was possible she had been for many years a "certified" patient diagnosed as schizophrenic and regarded as chronic and incurable. Furthermore, attitudes to and theories of mental illness being what they were, the relation of the subfrontal mass to her abnormal mental state might even then not have been appreciated as one of cause and effect, and operation not contemplated because of the "psychosis."

These patients were investigated under the care of Dr. C. J. Earl (Case 3, NH A20717) and Professor R. W. Gilliatt (Case 1, NH A11878, and Case 2, NH A19510) and operated on by Mr. Harvey Jackson and Mr. L. S. Walsh, whom we thank for access to case notes. The illustrations were prepared by the Department of Medical Illustration of the National Hospital.

\section{REFERENCES}

Andrew, J., and Nathan, P. W. (1964). Brain, 87, 233.

Arseni, C., Botez, M. I., Alexandru, S., and Simionescu, M. D. (1966). Int. F. Neurol., 5, 430.

Bickerstaff, E. R., Small, J. M., and Guest, I. A. (1958). F. Neurol. Neurosurg. Psychiat., 21, 89.

Blackburn, I. W. (1903). Intracranial Tumors among the Insane. Washington.

Bleuler, M., Willi, J., and Bühler, H. R. (1966). Akute psychische Begleiterscheinungen körperlicher Krankheiten. Stuttgart.

Bramwell, Byrom (1888). Intracranial Tumours. Edinburgh.

Bright, R. (1831). Reports of Medical Cases, Vol. 2, Diseases of the Brain and Nervous System. London.

Bucknill, J. C., and Tuke, D. H. (1879). A Manual of Psychological Medicine, 4 th ed. London.

Cushing, H. (1938). Meningiomas. Springfield, Illinois.

Faust, C. (1966). Int. \}. Neurol., 5, 410.

Hoffman, J. L. (1937). Psychiat. Quart., 11, 561.

Huber, A. (1961). Eye Symptoms in Brain Tumors, translated by S. van Wien. St. Louis.

Janz, D. (1964). f. neurol. Sci., 1, 446.

Kelly, R. (1951). Brain, 74, 23.

Klotz, M. (1957). Psychiat. Quart., 31, 669.

Larson, C. P. (1941). Amer. F. Psychiat., 97, 49.

Le Beau, J., Choppy, M., Gaches, J., and Rosier, M. (1954). Psychochirurgie et Fonctions Mentales. Paris.

Lhermitte, J. (1.951). Les Hallucinations. Paris.

Logue, V., Durward, M., Pratt, R. T. C., Piercy, M., and Nixon, W. L. B. (1968). Brit. F. Psychiat., 114, 137. 
McIntyre, H. D., and McIntyre, A. P. (1942). Amer. F. Psychiat., 98, 720.

Malherbe (1833). Sur les Tumeurs qui se développent dans l'Intérieur du Crâne. Thèse de Paris

Morse, M. E. (1920). Arch. Neurol. Psychiat. (Chic.), 3, 417.

Olivecrona, H. (1934). Die parasagittalen Meningeome. Leipzig.

Patton, R. B., and Sheppard, J. A. (1956). Amer. F. Psychiat., 113, 319.

Redlich, E. (1912). Die Psychosen bei Gehirnerkrankungen. Leipzig.

Russell, D. S., and Rubinstein, L. J. (1959). Pathology of Tumours of the Nerious System. London.

Selecki, B. R. (1964). Med. F. Aust., 2, 954.
Smith, S., and Hemphill, R. E. (1956). Y. Neurol. Neworosurg. Psychion., $19,42$.

Soniat, T. L. L. (1951). Amer. Y. Psychiat., 108, 19.

Waggoner, R. W., and Bagchi, B. K. (1953-4). Amer. F. Psychiat., 110, 904. Wilson, S. A. K. (1940). Neurology, edited by A. N. Bruce, vol. 2.

Wood, M. W., White, R. J., and Kernohan, J. W. (1957). 9. Neuroparh. exp Neurol., 16, 337.

Zülch, K. J. (1951). Die Hirngeschwülste in biologischer wand morphologischer Darstellung. Leipzig.

\title{
The Elderly in the Wrong Unit
}

\author{
ALEX G. MEZEY,* M.D., M.R.C.P.ED., D.P.M. ; H. M. HODKINSON, $†$ M.A., B.M., M.R.C.P. \\ GRAHAM J. EVANS, $\ddagger$ M.B., D.P.M.
}

Brit. med.F., 1968, 3, 16-18

\begin{abstract}
Cummary : Patients over 65 admitted from an area of $S$ North London forming the overlapping part of the catchment areas of a geriatric unit and a psychiatric unit were studied, with particular reference to misplacement in the inappropriate hospitals service and its consequences.
\end{abstract}

The incidence of misplacement found was much lower than previously reported. In the geriatric unit $2.2 \%$ of admissions were definitely and $6.0 \%$ were probably misplaced. In the psychiatric unit $6.2 \%$ were definitely and a further $8.4 \%$ were probably misplaced. Misplacement did not materially affect the outcome. The striking differences that were found between the patterns of death and discharge in the geriatric and psychiatric units were determined principally by the type of illness leading to admission.

The frequent coexistence of mental and physical disorders in the elderly patient, which this study confirms, indicates the need for further development of effective liaison at a local level between the geriatric, psychiatric, and social services.

\section{Introduction}

Recent thinking on geriatric services has favoured the establishment of assessment units with subsequent disposal of patients according to their needs. Much of this thought has been influenced by the findings of Kidd (1962a) in his study of old people in Belfast. He found that a large number of geriatric patients suffered both mental and physical illness, that many were admitted to the inappropriate hospital, and suggested that the prognoses of these patients were worse as a result (Kidd, 1962b).

The present paper describes part of a study designed to explore the need for such an assessment unit. It was carried out in the densely populated working-class boroughs of Tottenham and Edmonton (total population 204,205, with 25,376 aged 65 years and over at the 1961 Census) in North London. This is the only overlapping part of two much more extensive and independently run geriatric and psychiatric services; it is divided between two different local authorities. The geriatric

\footnotetext{
* Consultant Psychiatrist.

† Consultant Geriatrician.

$¥$ Research Assistant.

North Middlesex Hospital, London N.18.
}

service, to be referred to subsequently as the geriatric unit, has 181 admission beds (at the North Middlesex Hospital, Edmonton, and at St. Ann's General Hospital, Tottenham), with another 79 beds in long-stay annexes. The psychiatric service, which will be called the psychiatric unit, has 77 geriatric admission beds at Claybury Hospital, Essex, with a small number of additional beds in general psychiatric admission wards at the North Middlesex Hospital and at Claybury Hospital. There are also a large number of long-stay beds at Claybury Hospital.

\section{Methods}

Patients aged 65 and over from Tottenham or Edmonton who were admitted to the geriatric or psychiatric unit in the year from 8 May 1965 to 7 May 1966 were the subjects of the study. All admissions to the psychiatric unit were included, but a one-in-four random sample of admissions to the geriatric unit was taken so as to have roughly equal numbers. Within the first few days of admission the patients received a full psychiatric and medical examination, based on a standard form designed after a pilot study. Their behaviour was assessed separately by one of us (G. J. E.) and by the nursing staff, and recorded on the Crichton Royal Behaviour Rating Scale (Robinson, 1959). The Inglis Paired Associate Test (Inglis, 1959) was used in some cases. When necessary, patients' relatives were interviewed and their homes visited.

The course of each patient's illness was followed, and on discharge from hospital their behaviour was again assessed on the same behaviour rating scale. Six months after admission the outcome of each patient was recorded, and those who were alive were interviewed and their condition was assessed on a standard form. The results were transferred to punched cards for analysis.

The patients were classified in four different groups according to Kidd's terminology: (1) mental, (2) mental-physical, (3) physical-mental, and (4) physical. Patients in group 1 were diagnosed as suffering from psychiatric disorders only, and patients in group 4 from somatic disorders only. Patients in groups 2 and 3 were suffering from both psychiatric and somatic disorders, the first-mentioned being the main condition leading to hospital admission. Therefore in the geriatric unit groups 1 and 2 were misplaced; and in the psychiatric unit groups 3 and 4 were misplaced. One of us (G.J.E.) examined and assigned individual patients to one of the four groups, but difficult or borderline cases were placed after discussion 